\title{
Family Support in Sleep Apnea Patients using Continuous Positive Airway Pressure in Durango, Mexico
}

\author{
Posada-Valdez J I ${ }^{1 *}$, Rodríguez-Marín $\mathrm{ZF}^{1}$ and \\ Neri-Aragon IA $^{2}$ \\ ${ }^{1}$ Department of Family Medicine, General Hospital Zone \\ with Family Medicine \#1 (IMSS), Mexico \\ ${ }^{2}$ Department of Family Medicine, Family Medicine Unit \\ \#44 (IMSS), Mexico \\ *Corresponding author: Posada-Valdez JI, \\ Department of Family Medicine, General Hospital Zone \\ with Family Medicine \#1 (IMSS), Durango Delegation, \\ Mexico. J uarez University of the State of Durango, \\ Montevideo Street \# 409, Fracc. Guadalupe, C.P. 34220, \\ Durango, Dgo. Mexico
}

Received: December 27, 2020; Accepted: February 22, 2021; Published: March 01, 2021

\begin{abstract}
Introduction: Obstructive Sleep Apnea Syndrome (OSAS) is a sleep disorder with a high prevalence in Mexico of $3 \%$; His treatment of choice is the Continuous Positive Airway Pressure (CPAP) device. Family support is fundamental and undeniable for the patient in his life, his development, his illness and adherence to treatments.

Objective: The purpose of this study is to identify family support in patients with OSAS who use CPAP in Durango, Mexico.

Design and Setting: descriptive, cross-sectional and observational study

Material and Method: In 99 patients from the General Hospital of the Zone with Family Medicine \# 1 with a diagnosis of OSAS who use CPAP, the family APGAR test was performed to assess family support and the monthly CPAP reading report was reviewed. For the statistical analysis, an association was established with the chi-square test for statistical significance, a $95 \%$ confidence interval was used $(p<0.05)$.

Results: Of the 99 patients, family support was observed in $86.9 \%$ $(p=0.359)$ of the population studied, while $13.1 \%$ did not observe family support. $92.9 \%(n=92)$ of the patients adhere to CPAP, of which $86.9 \%(p=0.0001)$ have family support and $6.1 \%$ do not.

Conclusion: Family support is present in patients with OSAS who use CPAP, being important for the adherence and evolution of the disease.

Keywords: Family Support; Obstructive sleep apnea; Continuous Positive Pressure in the Airway
\end{abstract}

\section{Introduction}

At present, Obstructive Sleep Apnea Syndrome (OSAS) is a medical condition that we must recognize at the first level of medical care due to its comorbidity with diseases such as obesity, diabetes mellitus and cardiovascular diseases.

\section{Obstructive sleep apnea}

Within the International Classification of Sleep Disorders (ICSD) OSAS is a sleep-related respiratory disorder, characterized by partial or total obstruction of the airway causing periods of decreased oxygen saturation in the blood, causing cardiovascular problems , neurological, among others. Within its treatment, the mechanical device of Continuous Positive Airway Pressure (CPAP) in its acronym in English, is the one of choice, the most used and the most effective for OSA [1-3].

The prevalence of OSAS worldwide, both in the United States of America and Europe, does not vary from that of Mexico, it ranges by $3 \%$, men between $4-6 \%$ and in women between $2-4 \%$ in the middle age and increases with age at approximately 60-70 years [4]. In Mexico, OSAS has a high prevalence of $3 \%$ in men and $2 \%$ in women [4]. The National Institute of Medical Sciences and Nutrition "Dr Salvador Zubiran "(INCMNSZ) comments that $98 \%$ of patients with morbid obesity who attend this hospital will suffer from this sleep disorder [4-5]. In Mexico City, through questionnaire and respiratory polygraphy, an OSAS prevalence of $2.2 \%$ in women and $4.4 \%$ in men was estimated. This estimate rises exponentially with increasing Body Mass Index (BMI), reaching up to $10 \%$ in patients with a BMI greater than $40 \mathrm{~kg} / \mathrm{m}^{2}[4]$.

In the 2016 National Health and Nutrition Survey (ENSANUT 2016) the prevalence of overweight and obesity in adults over 20 years of age is $72.6 \%$, this prevalence is higher in women than in men [6]. Due to this alarming figure, we must consider OSAS as an important disease.

\section{Family support and functioning}

The family in general terms is dynamic in its composition, in assuming roles, in establishing limits, hierarchy, centrality and communication between subsystems; Faced with this dynamic, the family adjusts to circumstances and crises such as illnesses, child rearing, education, etc. Therefore, the members of the family, especially in the crises that are experienced in the disease processes, generally come together, show support and give support to the family member who suffers the disease and even to the family members who are most affected by this process $[7,8]$.

The disease disorganizes the family system from its acceptance to adherence to treatment, generating imbalances in the system where
J Fam Med - Volume 8 Issue 1 - 2021

ISSN : 2380-0658 | www.austinpublishing group.com

Posada-Valdez et al. @ All rights are reserved
Citation: Posada-Valdez JI, Rodríguez-Marín ZF and Neri-Aragon IA. Family Support in Sleep Apnea Patients using Continuous Positive Airway Pressure in Durango, Mexico. J Fam Med. 2021; 8(1): 1239. 
family support is very important for development and its favorable evolution. The concept of family support is understood to be the help and/or support provided by the family to face the stress caused by the crisis [7]. It should be clarified that family support and functionality is not the same concept, support is a family resource so that there is functionality in the family system.

When an individual becomes ill, it dramatically affects family functioning, just as the family influences the development of the health of its members; [7] then, family homeostasis is given by a functional family when facing, solving and adapting to events or crisis of the stages of the family life cycle $[7,8]$. And since the family is a system, the family support that the patient receives when they get sick is essential. Due to previous knowledge, the objective of this study is to identify family support in patients with OSAS who use CPAP in Durango, Mexico.

\section{Material and Methods}

A descriptive, cross-sectional, prospective and observational study was carried out in the General Hospital of Zone with Family Medicine \#1, of the Mexican Institute of Social Security (IMSS), located in Durango, Mexico; A non-probabilistic convenience sampling was carried out that met the following inclusion criteria: patients over 18 years of age, diagnosed with OSAS using CPAP, assigned to the Family Medicine outpatient clinic of the General Hospital of Zone with Family Medicine \#1 who agreed to participate and signed an informed consent; Patients with substance addiction disorders such as alcohol, tobacco and psychotropic drugs were not included; and those that do not have the monthly CPAP compliance report. Those who did not complete the survey or those who decided to voluntarily leave the study were eliminated.

The following data were obtained directly from the patients: age, sex, education, type of family, Family APGAR test result, and the monthly CPAP compliance report. The procedure for data collection was carried out by filling in the data collection sheet and answering the family APGAR test by the patient. The adherence to CPAP was obtained from the monthly CPAP compliance report, patients must use CPAP all the time they sleep, at least 4 hours per night, 5 or more nights per week, the pressure levels of each night, the presence of circuit leakage and residual respiratory events. The efficacy of CPAP depends on adherence to treatment [9-11].

Once the information was obtained through the surveys and the data was concentrated, the descriptive analysis, the elaboration of the frequency tables, the contingency tables and the Chi-square analysis, were carried out in the SPSS 21 statistical program. Descriptive and inferential statistics using frequency and percentage tables to analyze patients. Also measures of central tendency such as mean, median, standard deviation and variance for the quantitative variables. A p $<0.05$ was considered statistically significant, with a $95 \%$ confidence interval.

\section{Results}

We analyzed a total of 99 patients, of which 65 (65.7\%) were men and $34(34.3 \%)$ were women. The average age was $56.37 \pm 12.43$ years, the minimum registered age is 26 years, the maximum of 78 years. In relation to schooling, $24.2 \%$ of patients have primary education, $13.1 \%$ secondary, $20.2 \%$ high school, $42.4 \%$ bachelor's degree. Regarding

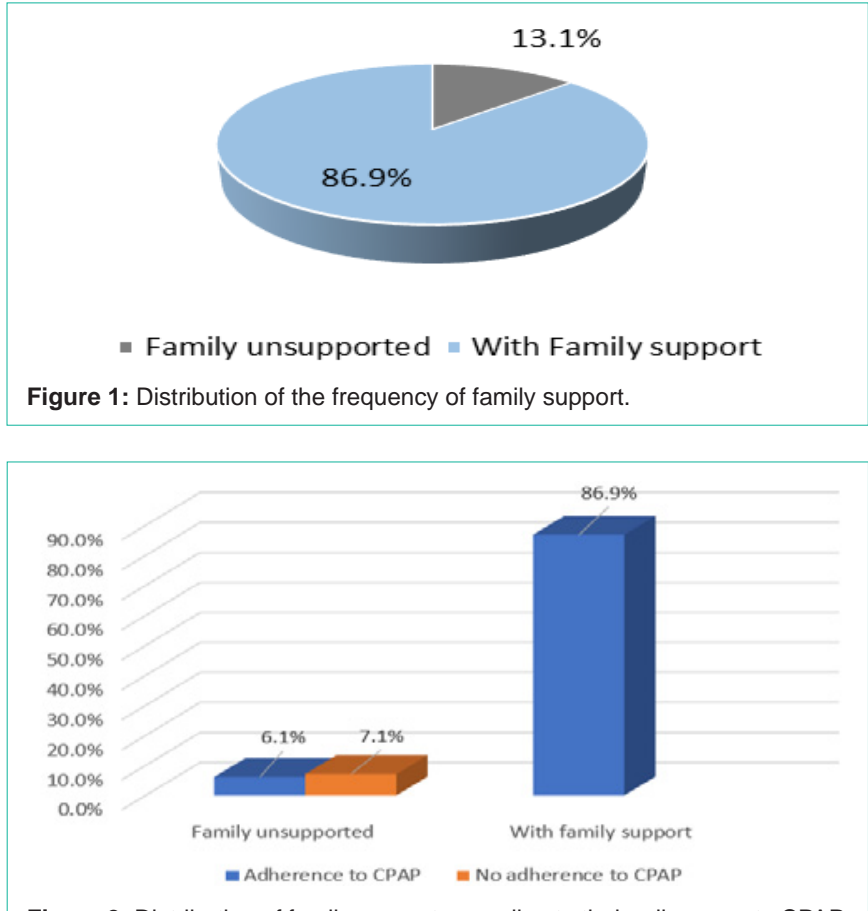

Figure 2: Distribution of family support according to their adherence to CPAP.

the family typology, $28.3 \%$ belong to a nuclear family; $56.6 \%$ to a simple nuclear family, $8.1 \%$ to a single parent family, $4 \%$ to an extended single parent family and $3 \%$ to a composite extended family. Analyzing the monthly CPAP compliance report, the adherence of patients to CPAP reported that $92.9 \%$ of patients use CPAP for more than 4 hours/day (70\% greater than the monthly use of CPAP), that is, they have adherence to CPAP; and $7.1 \%$ use less than 4 hours/day (70\% less than the monthly use of CPAP); that is, they do not adhere to CPAP (Table I) [9-11]. In relation to family support, we found that $86.9 \%$ of the patients did perceive family support, while $13.1 \%$ do not (Figure 1).

Regarding the CPAP adherence, 92.9\% of the patients have an adequate attachment, of which $86.9 \%$ perceive family support and $6 \%$ do not; while patients who do not perceive family support, $6.1 \%$ do adhere to CPAP, and $7.1 \%$ do not (Figure 2). As p-value $=0.0001$ and $<0.05$ (alpha), adherence to CPAP depends on the family support that patients receive (Table I). With a reliability of $95 \%$.

\section{Discussion and Conclusion}

There is currently no study in which family support is described in patients diagnosed with OSAS who use CPAP as treatment, however, in our study, when describing a specific objective about the patient's adherence to CPAP. Although, in the research article Spousal involment in CPAP adherence among patients with obstructive sleep apnea, it is mentioned that positive attachment to CPAP can be modified by the degree of commitment and the positive collaboration of the emotional grid (but not by their family) influencing the potential amelioration of adverse effects from the use of CPAP [9]. This research proves that there is family support in patients diagnosed with OSAS who use CPAP, assessing the patient's perception of their family's support for their disease. We can assure that the family plays an important role in the health-disease process of the patient with 
Table I: Contingency table of family support according to gender, age, education, family type and adherence to CPAP.

\begin{tabular}{|c|c|c|c|c|c|}
\hline \multirow{3}{*}{ Variables } & \multicolumn{4}{|c|}{ Family support } & \multirow{3}{*}{$\begin{array}{l}\text { p-value } \\
\text { Pearson's Chi- } \\
\text { square }\end{array}$} \\
\hline & \multicolumn{2}{|c|}{$\begin{array}{l}\text { No family } \\
\text { support }\end{array}$} & \multicolumn{2}{|c|}{$\begin{array}{l}\text { With family } \\
\text { support }\end{array}$} & \\
\hline & Frequency & $\%$ & Frequency & $\%$ & \\
\hline \multicolumn{6}{|l|}{ Gender } \\
\hline Male & 10 & 10.1 & 55 & 55.6 & \multirow{2}{*}{0.359} \\
\hline Female & 3 & 3 & 31 & 31.3 & \\
\hline \multicolumn{6}{|l|}{ Age (years) } \\
\hline $25-34$ & 0 & 0 & 6 & 6.1 & \multirow{6}{*}{0.249} \\
\hline $35-44$ & 4 & 4 & 9 & 9.1 & \\
\hline $45-54$ & 1 & 1 & 22 & 22.2 & \\
\hline $55-64$ & 5 & 5.1 & 25 & 25.3 & \\
\hline $65-74$ & 2 & 2 & 19 & 19.2 & \\
\hline $75-84$ & 1 & 1 & 5 & 5.1 & \\
\hline \multicolumn{6}{|l|}{ Education } \\
\hline Primary & 4 & 4 & 20 & 20.2 & \multirow{4}{*}{0.159} \\
\hline High school & 0 & 0 & 13 & 13.1 & \\
\hline Preparatory & 5 & 5.1 & 15 & 15.2 & \\
\hline University & 4 & 4 & 38 & 38.4 & \\
\hline \multicolumn{6}{|l|}{ Family Type } \\
\hline Nuclear & 4 & 4 & 24 & 24.2 & \multirow{5}{*}{0.689} \\
\hline Simple nuclear & 6 & 6.1 & 50 & 50.5 & \\
\hline Single parent & 2 & 2 & 6 & 6.1 & \\
\hline $\begin{array}{c}\text { Extended single } \\
\text { parent }\end{array}$ & 1 & 1 & 3 & 3 & \\
\hline $\begin{array}{l}\text { Extensive } \\
\text { compound }\end{array}$ & 0 & 0 & 3 & 3 & \\
\hline \multicolumn{6}{|l|}{$\begin{array}{l}\text { Adherence to } \\
\text { CPAP }\end{array}$} \\
\hline Yes & 6 & 6 & 86 & 86.9 & \multirow{2}{*}{0.0001} \\
\hline No & 7 & 7.1 & 0 & 0 & \\
\hline
\end{tabular}

OSAS since in this research we found that those patients who perceive family support have an $86.9 \%$ adherence to CPAP in relation to those who do not perceive family support (7.1\%), since the rest (6.1\%) of the patients who do not perceive family support don't adhere to CPAP.
In addition, $38.4 \%$ of patients who receive family support have undergraduate studies, as well as $50.5 \%$ make up a simple nuclear family, being a factor that can make a difference in the perception of family support by the patient.

\section{References}

1. Thorpy M. Classification of Sleep Disorders. Neurotherapuetics. 2012; 9: 687-701.

2. Torres-Valdez SS, Alva y Pérez JL. CPAP, a 30 anos de su descripcion como tratamiento de la apnea del sueño. Neumol Cir Torax. 2011; 70: 267-279.

3. Willman $M$, Igelström $H$, Martin $C$, Asenlof $P$. Experiences with CPAP treatment in patients with obstructive sleep apnea syndrome and obesity. Advances in Physiotherapy. 2012; 14: 166-174.

4. Carrillo JL, del Bosque FMA, Zuniga MR, Maldonado AS, Garcia JCV, TorreBouscoulet L. Síndrome de apnea obstructiva del sueño en población adulta. Neumol Cir Torax. 2010; 69: 103-115.

5. Valencia M, Rebollar GV, Orea TA, Castano-Meneses A, Garica-Ramos G, Gonzalez-Barranco J. Apnea del sueno en el paciente obeso. Revista de Endocrinología y Nutricion. 2011; 9: 97-102.

6. Hernández $M$, et ál. Encuesta Nacional de Salud y Nutrición en Medio Camino 2016. Secretaría de Salud. México. 2016:133.

7. Huerta J. Medicina familiar. La familia en el proceso salud-enfermedad.1a ed. México: Alfil; 2005.

8. Membrillo A, Fernández MA, Quiroz JR, Rodríguez JL. Familia Introducción al estudio de sus elementos. $1^{\mathrm{a}}$ ed. México: Editores de Textos Mexicanos; 2008.

9. Smith TW, et ál. Spousal involment in CPAP adherence among patients with obstructive sleep apnea. Sleep Breath. Epub. EE.UU. 2010;15(3):525-34.

10. Nogueira J, Borsini E, Nigro C. Estrategias para mejorar la adaptación al tratamiento con CPAP en pacientes con SAHOS. Rev Am Med Respir. 2016;16(4):1-4

11. Rute S, M. Graça $P$, Joào CW. Obstructive sleep apnea representations, selfefficacy and family coping regarding APAP adherence: a longitudinal study. Psychology, Health \& Medicine. 2014; 19(1):59-69. 